\title{
Transient hyperphosphatasaemia in association with acute infection in adults
}

\author{
S.G. Parker* \\ Ashington Hospital, West View, Ashington, Northumberland, UK
}

\begin{abstract}
Summary: The causes of raised serum alkaline phosphatase were determined prospectively in a consecutive series of 2884 acute medical admissions. Diagnoses were established by pre-defined clinico-pathological criteria. Two hundred and four patients had hyperphosphatasaemia. Liver and bone disease accounted for only $98(48 \%)$ of the established diagnoses. The diagnosis was not established in 31 (15\%). Transient hyperphosphatasaemia occurred in $66(32.4 \%)$ cases. In 25 of these patients $(12 \%$ of the total) an acute infection was the sole illness identified. In this infected group, the isoenzyme type was predominantly hepatic, although jaundice occurred in only 3 patients. Discriminant analysis revealed that this group was characterized by haematological and biochemical features of an acute phase response.

Transient hyperphosphatasaemia is commonly found in acutely ill medical inpatients and is frequently associated with acute extrahepatic infection.
\end{abstract}

\section{Introduction}

The causes of raised serum alkaline phosphatase (ALP) are well documented and widely known. The most frequent causes of raised ALP are liver disease, bone disease and hepatic congestion secondary to heart failure ${ }^{1,2}$ Often, however, the cause of hyperphosphatasaemia is not found and the liver fraction of serum alkaline phosphatase may be elevated without clinically apparent liver disease. ${ }^{3}$ Raised serum alkaline phosphatase may be associated with acute infection but descriptions of this phenomenon are confined to occasional case reports ${ }^{4}$ or selected groups (such as the elderly). ${ }^{5}$ Transient hyperphosphatasaemia, in the absence of jaundice and in association with acute infection, is shown, in this study, to occur commonly in a series of acute general medical admissions. It is not a well recognized cause of hyperphosphatasaemia in adults and its prevalence in acutely ill medical patients was previously unknown.

\footnotetext{
*Correspondence and present address: S.G. Parker, M.D., M.R.C.P. (UK), Department of Medicine (Geriatrics), University of Newcastle upon Tyne, Floor 4 - William Leech Building, Framlington Place, Newcastle upon Tyne NE2 4HH, UK.

Accepted: 5 February 1991
}

\section{Patients and methods}

A consecutive series of acute medical admissions to a district general hospital (Ashington Hospital,? Northumberland) were screened on admission for raised serum ALP. The reference limits for this laboratory are 30-130 international units (IU) per litre. A level of $>150 \mathrm{IU} / 1$ on admission was defined as raised for the purposes of this study. ALP was measured using para-nitrophenol as substrate in amino methyl propanol buffer ( $\mathrm{pH}$ 9.3) using a Cobas Bio centrifugal analyser. The within assay coefficient of variation for the method was $1.3 \%(n=10)$ and between assay $2.3 \%(n=7)$. Alkaline phosphatase isoenzyme type was determined by polyacrylamide gel electrophoresis. ${ }^{6}$

Measurement of serum alkaline phosphatase was repeated as clinically appropriate and prior to discharge. Patients in whom the cause was not found as an inpatient, whose ALP remained elevated at discharge, were invited to a follow-up clinic dedicated to the purpose of establishing the cause of their raised serum alkaline phosphatase. Investigation both as an inpatient and at the follow-up clinic was directed towards satisfying the diagnostic criteria outlined below by the use of pre-defined investigative pathways. Patients were placed into one of six diagnostic categories after appropriate specific investigations according to the following criteria:

Liver disease - histological evidence of parenchymal liver disease. Cholangiographic evidence of 
biliary tract disease. Except: hepatitis A (serological evidence), hepatic metastasis (ultrasonography).

Bone disease - X-ray of symptomatic site or site suggested by isotope scanning either produced radiological evidence of Paget's disease or metastasis, or was followed by bone biopsy to obtain a histological diagnosis.

Transient elevation - if a primary liver or bone disease was not detected and ALP returned to normal within 3 months of admission to hospital, elevation was said to be transient and occurring in association with the disease causing the hospital admission. This group was further subdivided (post hoc) into those who had an acute infection as the sole illness identified [the transient (infection) group] and those who had non-infective disorders such as congestive cardiac failure, or multiple illnesses including an acute infection [the transient (other) group].

Other causes - these were all well recognized but uncommon causes of raised serum ALP (e.g. non-metastatic hypernephroma, Hodgkin's disease). Unknown - patients who died (without necropsy) prior to establishing the diagnosis, who failed to attend for follow up after 3 invitations or who failed to meet the diagnostic criteria.

One way analysis of variance and stepwise discriminant analysis were performed using an
IBM compatible microcomputer equipped with SOLO statistical software (BMDP Statistical Software, Inc.). ${ }^{?}$

The study protocol was approved by the local ethical committee.

\section{Results}

Two hundred and four of 2884 patients screened had raised serum ALP (7.1\%). The major diagnostic categories into which these patients fell is shown in Table I. It can be seen that transient changes in serum alkaline phosphatase activity are common in this group of unselected general medical admissions, heart failure and acute infection being the most frequent diagnoses. However, not all patients who presented initially with either heart failure or acute infection had transiently raised ALP. Twenty-two patients with these initial diagnoses were subsequently shown to have persistently raised ALP due to hepatic metastases (3) and bone disease (8), 11 remained undiagnosed.

In all, $\mathbf{3 0}$ of the group with transient hyperphosphatasaemia (all causes) had an acute infection. In 25 of this group the acute infection was the sole illness identified. These 25 patients were accordingly allocated to the transient (infection) group for subsequent analysis. The infections were pneu-

Table I Group allocation, age and biochemical variables in 204 patients with raised serum alkaline phosphatase $(>150 \mathrm{IU} / \mathrm{l})$

\begin{tabular}{|c|c|c|c|c|c|c|c|c|c|c|c|}
\hline Diagnostic group & $n$ & Age & $A L P$ & $H b$ & $W C C$ & $E S R$ & Bilirubin & Albumin & Globulin & $A S T$ & $G G T$ \\
\hline Liver & 63 & $\begin{array}{c}66.1 \\
(13.7)\end{array}$ & $\begin{array}{c}284 \\
(180)\end{array}$ & $\begin{array}{l}12.3 \\
(2.6)\end{array}$ & $\begin{array}{c}11.2 \\
(8.3)\end{array}$ & $\begin{array}{c}43 \\
(34)\end{array}$ & $\begin{array}{c}44 \\
(76)\end{array}$ & $\begin{array}{c}36 \\
(5.0)\end{array}$ & $\begin{array}{c}34 \\
(7.5)\end{array}$ & $\begin{array}{c}111 \\
(234)\end{array}$ & $\begin{array}{c}307 \\
(372)\end{array}$ \\
\hline Bone & 29 & $\begin{array}{c}74.0 \\
(11.5)\end{array}$ & $\begin{array}{c}510 \\
(748)\end{array}$ & $\begin{array}{l}12.3 \\
(1.6)\end{array}$ & $\begin{array}{r}8.1 \\
(3.0)\end{array}$ & $\begin{array}{c}36 \\
(30)\end{array}$ & $\begin{array}{l}10 \\
(8)\end{array}$ & $\begin{array}{c}38 \\
(5.5)\end{array}$ & $\begin{array}{c}31 \\
(5.2)\end{array}$ & $\begin{array}{c}41 \\
(49)\end{array}$ & $\begin{array}{c}97 \\
(145)\end{array}$ \\
\hline Liver and bone & 6 & $\begin{array}{c}70.2 \\
(24.3)\end{array}$ & $\begin{array}{c}254 \\
(124)\end{array}$ & $\begin{array}{l}12.5 \\
(1.4)\end{array}$ & $\begin{array}{r}7.9 \\
(2.6)\end{array}$ & $\begin{array}{c}32 \\
(34)\end{array}$ & $\begin{array}{l}10 \\
(4)\end{array}$ & $\begin{array}{c}37 \\
(6.9)\end{array}$ & $\begin{array}{c}28 \\
(7.1)\end{array}$ & $\begin{array}{c}61 \\
(74)\end{array}$ & $\begin{array}{c}165 \\
(120)\end{array}$ \\
\hline Other & 9 & $\begin{array}{l}62.6 \\
(9.5)\end{array}$ & $\begin{array}{c}273 \\
(133)\end{array}$ & $\begin{array}{r}12.3 \\
(4.6)\end{array}$ & $\begin{array}{c}70.8 \\
(148)\end{array}$ & $\begin{array}{c}49 \\
(52)\end{array}$ & $\begin{array}{c}17 \\
(10)\end{array}$ & $\begin{array}{c}34 \\
(9.1)\end{array}$ & $\begin{array}{c}29 \\
(10.1)\end{array}$ & $\begin{array}{c}69 \\
(77)\end{array}$ & $\begin{array}{c}164 \\
(166)\end{array}$ \\
\hline No diagnosis & 31 & $\begin{array}{c}72.8 \\
(13.9)\end{array}$ & $\begin{array}{c}255 \\
(127)\end{array}$ & $\begin{array}{l}12.8 \\
(2.8)\end{array}$ & $\begin{array}{r}10.3 \\
(4.9)\end{array}$ & $\begin{array}{c}31 \\
(25)\end{array}$ & $\begin{array}{c}16 \\
(22)\end{array}$ & $\begin{array}{c}35 \\
(4.5)\end{array}$ & $\begin{array}{c}32 \\
(5.6)\end{array}$ & $\begin{array}{c}86 \\
(292)\end{array}$ & $\begin{array}{c}167 \\
(264)\end{array}$ \\
\hline $\begin{array}{r}\text { Transient infection } \\
\text { other }\end{array}$ & $\begin{array}{l}25 \\
41\end{array}$ & $\begin{array}{c}68.6 \\
(14.3) \\
69.6 \\
(10.1)\end{array}$ & $\begin{array}{l}221 \\
(71) \\
253 \\
(153)\end{array}$ & $\begin{array}{l}11.7 \\
(2.4) \\
13.0 \\
(2.7)\end{array}$ & $\begin{array}{c}13.9 \\
(5.1) \\
15.1 \\
(31.1)\end{array}$ & $\begin{array}{c}74 \\
(34) \\
24 \\
(27)\end{array}$ & $\begin{array}{c}19 \\
(27) \\
20 \\
(22)\end{array}$ & $\begin{array}{c}31 \\
(5.0) \\
37 \\
(6.4)\end{array}$ & $\begin{array}{c}33 \\
(6.3) \\
32 \\
(5.9)\end{array}$ & $\begin{array}{c}59 \\
(51) \\
97 \\
(168)\end{array}$ & $\begin{array}{c}143 \\
(157) \\
194 \\
(263)\end{array}$ \\
\hline \multicolumn{12}{|l|}{ Analysis of variance } \\
\hline$P$ & & 0.08 & 0.08 & 0.602 & $<0.001$ & $<0.001$ & 0.01 & 0.003 & 0.22 & 0.76 & 0.043 \\
\hline
\end{tabular}

All variables expressed as mean (standard deviation). Enzyme activities are expressed as international units per litre, albumin and globulin $\mathrm{g} / \mathrm{l}$, haemoglobin $\mathrm{g} / \mathrm{dl}$, white cell count as cell $\times 10^{9} / 1$, bilirubin $\mu \mathrm{M} / \mathrm{l}$. One way analysis of variance was performed for each individual variable by group with 6 degrees of freedom. ALP-alkaline phosphatase; Hb-haemoglobin; WCC-white cell count; ESR-erythrocyte sedimentation rate; AST-serum aspartate transaminase; GGT-gamma glutamyl transferase. 
monia (in 13 patients), abscesses (3), skin (3), joint (3), urinary tract (2) and septicaemia (1). The age of this group did not differ significantly from that of the other groups (Table I), 3 patients were jaundiced; 12 had raised serum aspartate transaminase (AST), 15 had raised gamma glutamyl transferase (GGT). Twenty of 21 patients in whom it was measured had predominantly liver isoenzyme by polyacrylamide gel electrophoresis.

The biochemical diagnosis of transient hyperphosphatasaemia in association with acute infection was further characterized by one way analysis of variance and discriminant analysis. One way analysis of variance revealed that there were significant differences between groups with respect to white cell count (WCC), erythrocyte sedimentation rate (ESR), serum bilirubin, albumin and GGT (Table I).

The same haematological and biochemical variables were entered into a series of discriminant analyses comparing the transient (infection) group with the other groups in turn to see if there was a distinguishing pattern of haematological or biochemical results. The 'liver + bone', and 'other' groups were excluded because they contained too few patients for a meaningful comparison to be made and 'no diagnosis' was treated as a missing value for group classification.

For each analysis variables were entered stepwise in order of significant contribution to group membership until all of the unused variables failed to meet the criteria of significance $(P<0.05)$. The prior probabilities were adjusted according to group size. The linear discriminant functions derived from this analysis were used to classify individual patients and calculate the standard classification merit statistics presented in Table II.

\section{Discussion}

This study has shown that raised serum alkaline phosphatase occurs commonly in acutely ill medical inpatients. It emphasizes the observation that transient hyperphosphatasaemia is common in this population. Transient hyperphosphatasaemia is shown to be associated with acute infection in $12 \%$ of cases. This group was distinguished from the other major diagnostic groups by the haematological and biochemical features of an acute phase response (raised WCC and ESR, lowered serum albumin) and lower levels of GGT and bilirubin (reflecting the predominance of hepatic dysfunction among the liver and transient (other) groups).

Although inter-individual variation in serum alkaline phosphatase is large (hence the wide reference range), day to day variation within individuals is known to be remarkably small, and assay variation (of 3-5\%) accounts for approximately $50 \%$ of apparent intrasubject variation for the enzyme. ${ }^{8}$ For this reason, and the fact that the initial alkaline phosphatase levels in the infected patients were $15 \%$ above the normal range when first measured, it is unlikely that the changes in serum alkaline phosphatase activity observed in these infected patients represent random variations or 'regression to the mean'.

It is well recognized that severe infection may be associated with abnormalities of liver function, including mild to moderate increases in serum? ALP, bilirubin and transaminases. ${ }^{3,5}$ These changes may occur in the absence of sepsis in the liver itself ${ }^{4}$ although reports of this phenomenon have largely been confined to patients with jaundice and severe sepsis. $^{9-12}$ Isolated raised serum ALP in acute infection is less well recognized. ${ }^{4,13}$

Table II Summary of discriminant analysis in which the transient (infection) group was compared to the other major groups

\begin{tabular}{|c|c|c|c|c|c|}
\hline Comparison & $\begin{array}{c}\text { Significant } \\
\text { variables }\end{array}$ & $P$ & Accuracy & $\begin{array}{c}\text { Classification } \\
\text { Sensitivity }\end{array}$ & Specificity \\
\hline All others $(n=132)$ & $\begin{array}{c}\text { ESR } \uparrow \\
\text { globulin } \uparrow \\
\text { albumin } \downarrow\end{array}$ & $\begin{array}{l}0.011 \\
0.017 \\
0.034\end{array}$ & $63 \%$ & $76 \%$ & $21 \%$ \\
\hline Liver disease $(n=63)$ & $\begin{array}{c}\text { ESR } \uparrow \\
\text { GGT } \downarrow \\
\text { globulin } \uparrow\end{array}$ & $\begin{array}{r}<0.001 \\
0.006 \\
0.032\end{array}$ & $50 \%$ & $70 \%$ & $46 \%$ \\
\hline Bone disease $(n=29)$ & $\underset{\text { WCC } \uparrow}{\operatorname{albumin}} \downarrow$ & $\begin{array}{r}<0.001 \\
0.019\end{array}$ & $50 \%$ & $87 \%$ & $62 \%$ \\
\hline Transient (other) $(n=41)$ & $\begin{array}{l}\text { ESR } \uparrow \\
\text { GGT } \downarrow\end{array}$ & $\begin{array}{r}<0.001 \\
0.029\end{array}$ & $57 \%$ & $87 \%$ & $76 \%$ \\
\hline
\end{tabular}

$\uparrow=$ higher, $\downarrow=$ lower in transient (infection) group. ESR-erythrocyte sedimentation rate;

GGT-gamma glutamyl transferase; WCC-white cell count. 
Abnormal 'liver function tests' were first reported to occur in association with pneumonia in $1950 .^{12}$ In a study of 94 cases of pneumococcal pneumonia, abnormal bromsulphthalein excretion was found in $81.5 \%$. Thirteen cases developed jaundice but no correlation was found between abnormal liver function tests and conventional measures of severity and outcome. Thirty patients were re-evaluated during convalescence and showed a reversion to normal patterns. Serum enzyme measurements were not made. It was concluded that liver function is widely and almost invariably impaired in pneumonia and suggested that this impairment may be mediated by the 'alarm reaction'.

Raised serum alkaline phosphatase has also been reported in patients with pneumonia ${ }^{4}$ and in surgical infection. ${ }^{14}$ In a study of pneumococcal pneumonia, ${ }^{15}$ serum alkaline phosphatase was found to be elevated in $9.4 \%$ of the non-jaundiced patients, $23 \%$ having raised serum aspartate transaminase. Ten out of 28 patients with jaundice had elevated serum alkaline phosphatase activities. Interpretation of this study is complicated by the high prevalence of glucose-6-phosphatase dehydrogenase deficency, which was present in $85.7 \%$ of the jaundiced patients.

Fang reported 4 cases of systemic infection who developed marked elevation of serum alkaline phosphatase in the absence of jaundice. ${ }^{16}$ She suggested a number of possible mechanisms by which this might occur, including non-specific effects of bacteria or their toxins, disturbance in transport and clearance of bilirubin, hepatic anoxia and reduced elimination because of 'reticuloendothelial blockade'.

Kaplan has suggested that alkaline phosphatase may in some circumstances behave as a nonspecific 'acute phase reactant'. ${ }^{17}$ This is an attractive hypothesis as it would encompass a number of Fang's possible mechanisms, diverse bacterial infections producing a common effect via the action of the acute phase cytokines. ${ }^{18}$

The distinguishing biochemical features of the infected group in this study are entirely consistent with the presence of an acute phase response. A high ESR, in the absence of immunoglobulin abnormalities is predominantly due to the fibrinogen content of the blood. Fibrinogen is a major positive acute phase reactant protein, showing a 2 - to 5 -fold rise in

\section{References}

1. Lubin, J.R., Coles, J.A., Millward, B.A. \& Croker, J.R. Value of profiling liver function in the elderly. Postgrad Med J 1983, 59: 763-766.

2. Parker, S.G., Carey, S.A., Skillen, A.W. \& Simpson, J.M. Serum alkaline phosphatase isoenyzmes. J Clin Pathol 1987, 40: 471-472. plasma concentration during an acute phase response. ${ }^{19}$ Similarly, depression of serum albumin level is a well recognized consequence of acute inflammation and is associated with a reduction in hepatic synthesis of this protein. ${ }^{20}$ The same stimuli that are responsible for alterations in hepatic metabolism (namely interleukin 1, interleukin 6 and tumour necrosis factor- $\alpha$ ) also cause the neutrophilia characteristic of acute infection.

Serum alkaline phosphatase may become elevated in other conditions in which the features of an acute phase response are prominent and for which there is currently no explanation. These conditions are aetiologically diverse but share the common features that fever, tissue necrosis or elevated levels of serum acute phase proteins are prominent and well recognized features. Examples include polymyalgia rheumatica, ${ }^{21}$ non-metastatic hypernephroma with fever, ${ }^{22}$ surgical infection ${ }^{12}$ and retroperitoneal fibrosis. ${ }^{23}$

If raised serum alkaline phosphatase is an 'acute phase' phenomenon then there must be a mechanism by which serum alkaline phosphatase of liver type might become elevated during an acute phase response. The accepted mechanism by which hepatic alkaline phosphatase rises in disease is via the action of bile acids in cholestasis. ${ }^{17}$ Hepatocyte alkaline phosphatase synthesis is induced by these substances and this process can be demonstrated experimentally in vivo in bile duct ligated animals ${ }^{24}$ and in vitro, in cultured hepatocytes. ${ }^{25}$ No such evidence exists for the action of inflammatory stimuli such as acute phase cytokines in these experimental models, either on biliary uptake and excretion or on hepatocyte alkaline phosphatase activity.

Whatever the mechanism involved, transient hyperphosphatasaemia in association with infection is common in acutely ill medical patients and should be considered before embarking on a search for liver or bone disease in acutely infected patients.

\section{Acknowledgements}

I would like to thank Dr A. Skillen for performing the alkaline phosphatase isoenzyme measurements, Drs E.T. Young, D.B. Banerjee, E.A. Cameron, P. Brown and P. Crook for allowing me to study their patients and Professor O.F.W. James for his helpful encouragement and advice.

3. Brensilver, H.L. \& Kaplan, M. Significance of elevated liver alkaline phosphatase in serum. Gastroenterology 1975, 68: 1556-1562.

4. Odeh, M.M. \& Bassan, H.M. Pleuropneumonia and alkaline phosphatase. Ann Intern Med 1988, 108: 644. 
5. Kenny, R.A., Hodkinson, H.M., Prendville, O.F., Hayes, M.C. \& Flynn, M.D. Abnormalities of liver function and the predictive value of liver function tests in infection and outcome of acutely ill elderly patients. Age Ageing 1984, 13: 224-229.

6. Skillen, A.W. \& Plerides, A.M. Serum alkaline phosphatase isoenzyme patterns in patients with chronic renal failure. Clin Chim Acta 1977, 1800: 399-402.

7. Hintze, J.L. SOLO Users Guide. BMDP Statistical Software, Los Angeles, 1988.

8. Pickup, J.F., Harris, E.K., Kearns, M. \& Brown, S.S. Intraindividual variation of some serum constituents and its relevance to population based reference ranges. Clin Chem 1977, 23: 842-850.

9. Fahrlander, H., Huber, F. \& Gloor, F. Intrahepatic retention of bile in severe bacterial infections. Gastroenterology 1964, 47: 590-599.

10. Eley, A., Hargreaves, T. \& Lambert, H.P. Jaundice in severe infections. Br Med J 1965, 2: 75-77.

11. Vermillion, S.E., Gregg, J.A., Baggenstoss, A.H. \& Bartholomew, L.G. Jaundice associated with bacteraemia. Arch Intern Med 1969, 124: 611-618.

12. Zimmerman, H.J. \& Lawrence, T.J. The liver in pneumococcal pneumonia: observations in 94 cases on liver function and jaundice in pneumonia. J Lab Clin Methods 1950, 35: $556-567$.

13. Chu, C.M. \& Liaw, Y.F. High serum alkaline phosphatase in septemic infection. Gastroenterology 1980, 79: 776.

14. Royle, M.S. \& Kettlewell, M.G.W. Liver function tests in surgical infection and malnutrition. Ann Surg 1980, 192: $192-194$.

15. Tugwell, P. \& Williams, A.O. Jaundice associated with lobar pneumonia. $Q J$ Med 1977, 46: 97-118.
16. Fang, M.H., Ginsberg, A.L. \& Dobbins, W.O. III. Marked elevation in serum alkaline phosphatase activity as a manifestation of systemic illness. Gastroenterology 1980, 78: 592-597.

17. Kaplan, M.M. Serum alkaline phosphatase - another piece is added to the puzzle. Hepatology 1986, 6: 526-528.

18. Dinarello, C.A., Interleukin 1 and its biologically related cytokines. Adv Immunol 1989, 44: 153-205.

19. Whicher, J.T., Thompson, D., Billingham, M.E.J. \& Kitchen, E.A. Acute phase proteins. In: Chang, J.Y. \& Lewis, A. (eds) Pharmacological Methods in the Control of Inflammation. Alan R. Liss, New York, 1989, pp. 101-128.

20. Hooper, D.C., Steer, C.J., Dinarello, C.A. \& Peacock, A.C Haptoglobin and albumin synthesis in isolated rat hepatocytes. Response to potential mediators of the acute phase response. Biochim Biophys Acta 1981, 653: 1118-1129.

21. Glick, E.N. Raised serum alkaline phosphatase levels in polymyalgia rheumatica. Lancet 1972 , ii: 328.

22. Shipman, K.H., Downing, S.W. \& Bradford, H.A. Hypernephroma presenting as fever of unknown origin associated with elevated serum alkaline phosphatase levels. J Urol 1963 , 89: $160-163$.

23. Barrison, I.G., Walker, J.G., Jones, C. \& Snell, M.E. Idiopathic retroperitoneal fibrosis - is serum alkaline phosphatase a marker of disease activity? Postgrad Med J 1988, 64: 239-241.

24. Seetharam, S., Sussman, N.L., Komoda, K. \& Alpers, D.H. The mechanism of elevated alkaline phosphatase activity after bile duct ligation in the rat. Hepatology 1986, 6: 374-380.

25. Hatoff, D.E. \& Hardison, G.M. Induced synthesis of alkaline phosphatase by bile acids in rat liver cell culture. Gastroenterology 1979, 77: 1062-1067. 